Current Research in Psychology 1 (1): 71-74, 2010

ISSN 1949-0178

(C) 2010 Science Publications

\title{
How (Un)biased are Airport Security Screening Procedures? A Social-Cognitive Experiment
}

\author{
Poornima Madhavan and Jeremy R. Brown \\ Department of Psychology, Old Dominion University, Norfolk, VA 23529
}

\begin{abstract}
Problem statement: This research examined the role that social-cognitive biases such as gender biases and racial biases play in decision making processes during the screening of carry-on luggage at airports. This research is unique in that no research so far has addressed the socialpsychological underpinnings of airport security screening procedures. Approach: Participants $(n=36)$ performed a computer simulated task wherein they played the role of luggage screeners and detected hidden weapons in $200 \mathrm{x}$-ray images of passenger luggage. Participants saw each luggage image for 3 sec, thereby simulating the high time pressure and short decision time characteristic of busy international airports. At the beginning of each trial and before observing the luggage, participants were shown the picture of the "passenger" to whom the luggage purportedly belonged for a brief exposure period. The passenger pictures were pre-tested and were representative of both genders and five different races (White, Black, Asian, Middle Eastern, Hispanic). After observing the passenger's picture, participants scanned the luggage and chose to either pass or stop the bag based on their diagnosis of weapon presence or absence. Results: Results revealed no significant differences in probability of correct detections as a function of passenger gender or race. However, the probability of generating false positives was significantly higher when the passenger was male; more importantly, this effect was observed for only two races-passengers of Middle Eastern or Hispanic origin. Conclusion/Recommendations: Participants purportedly depended heavily on their opinions of the passenger to make their decisions to pass or stop the bag when time pressure was high, almost as a heuristic replacement for visually scanning the bag under constrained situations. These results go beyond simple ingroup-outgroup differences discussed in social psychology; they point to deeply ingrained biases targeting specific demographic groups in the United States. These results are significant for airport security screening and the future of national security.
\end{abstract}

Key words: Luggage-screening, biases, gender, race, social psychology, cognition

\section{INTRODUCTION}

In the screening of carry-on luggage at airports, the primary task entails the screener to search through an x-ray image of luggage within a brief exposure period (2-6 sec depending on queue length) and stop a bag that might potentially contain a threat. A plethora of recent laboratory studies have examined ways to improve this screening process. Most studies have focused on pure cognitive aspects such as screener memory, learning and speed-accuracy tradeoffs (McCarley et al., 2004) or technology implementation to assist the screener.

Luggage screening, however, is seldom performed in isolation. One critical lacuna in existing research is an empirical evaluation of social-cognitive factors that might affect screener decisions to stop or pass carry-on luggage passing through the carousel. One of these involves the passenger that 'belongs' to the luggage and any biases the screener may have toward the passenger. It is frequently alleged that airport luggage screening procedures are biased by the characteristics of passengers themselves and are less influenced by the presence or absence of threat objects in the luggage per se. This is not necessarily wrong since there is some support for the fact that facial expressions (particularly those reflecting nervousness, restlessness and agitation) can be indicative of negative intentions (Bonanno et al., 2002); however, we contend that overreliance on such external "cues" to make diagnostic decisions in luggage screening can lead to serious false alarms and loss of time and energy for both screener and passenger. Answers to some simple but nevertheless important questions are still heresy and have not been empirically examined - did the passenger appear a certain way to arouse suspicion? Was the passenger of a particular

Corresponding Author: Poornima Madhavan, Department of Psychology, Old Dominion University, Norfolk, VA 23529 
race? Was the passenger a man or a woman? We discuss below the two variables that we contend are most likely to influence luggage screener decisionsgender and race of passengers.

Gender biases: When one gender is given preferential treatment over the other, it is typically referred to as "gender bias" (Baker et al., 2002). Gender bias is pervasive especially in the workplace. When men and women are evaluated for the same type of work, male workers have been found to get better rewards for good evaluations compared to female workers; on the flip side, male workers also receive harsher punishments than female workers in response to poor evaluations (McKay and Tate, 2001). Clearly, gender-related biases play a major role when decisions to hire, promote or fire are made in several job contexts.

Contrary to the apparent bias in favor of males in the workplace, men are also more likely to be associated with negative and destructive traits such as lying, stealing, aggression and physical violence. In 2006, public resources have revealed that there were $1,479,726$ men in state and federal prisons compared with only 115,308 women. This clearly indicates that men are being convicted of crimes more frequently than women; however these statistics could either suggest an actual tendency for men to be more violent than women or simply a tendency for men to be "perceived" as more violent than women.

Based on the above findings we hypothesize that in the context of carry-on luggage screening, screeners would be more suspicious of male passengers than female passengers and will be more likely to stop male passengers' baggage compared to female passengers' baggage. This introduces a gender bias into the luggage screening process based on the different traits that men and women purportedly possess.

Racial biases: Although we would like to think differently, racial bias is still prevalent throughout the world. There have been numerous studies looking at racial bias among police and their decisions to shoot or not shoot (Correll et al., 2007; Plant and Peruche, 2005). In the Correll et al. (2007) study, comparing police to civilians in the same district, civilians were found to be more likely to shoot when shown a suspect of minority race compared with the police. Both police and civilian participants, however, took longer to react when the White suspect had a gun and the minority suspect did not have a gun. The researcher concluded that seeing a White person with a gun violated people's expectations leading them to take longer to react; the opposite was true when observing a person of minority race who was perceived as dangerous even without a weapon in possession (Correll et al., 2007).

In carry-on luggage screening, racial bias can be manifested in how passengers get stopped by screeners as a function of their race. The studies described above show that there is a bias present among some police officers towards minority groups (Correll et al., 2007; Plant and Peruche, 2005). The same bias could be observed in the security officers at airports and would lead to passenger of minority races having their baggage stopped more often than White passengers' luggage no matter what the race of the screener is. The race of the screener could be an additional factor that determines whether or not they pass the passenger's luggage. Screeners that are screening luggage from a passenger of the same race may be more lenient toward them relative to a passenger of another race (Lee and Ottati, 2002). On the other hand, it is possible that all screeners, including screeners of minority races, may uniformly favor White passengers over passengers of minority races (Boldry and Kashy, 1999).

Purpose of the present study: The purpose of this laboratory study was to examine the effect of two key passenger characteristics on screeners' decisions to stop or pass luggage in a succinct manner. Specifically, the study involved manipulation of only two variablesgender and race of passengers-in order to allow us to clearly delineate the effects of these individual difference variables on screener performance. We hypothesized that luggage screening will be affected strongly by gender biases, leading to men being stopped more than women since there is greater evidence for men engaging in aggression and violence compared to women. In addition, we expected racial bias to be manifested in the screening process by minorities being stopped more often than passengers of the majority population.

\section{MATERIALS AND METHODS}

Participants: Thirty six undergraduate students (7 white men, 12 white women, 6 black men, 11 black women; mean age $=20.27$ years, $\mathrm{SD}=2.99$ ) completed the study for course credit. The study was approximately $1 \mathrm{~h}$ in duration.

Procedure: Participants performed the role of airline luggage screeners wherein they detected the presence of dangerous objects digitally superimposed in 200 x-ray images of luggage depicted on a computer screen. Participants began each block of 100 trials by memorizing five dangerous target objects. They then 
searched for any of these targets in the ensuing bags, each of which appeared on the screen for $3 \mathrm{sec}$, simulating high time pressure at busy international airports.

On each trial, the appearance of the luggage image was preceded by the picture of a passenger's face to whom the bag supposedly "belonged" (randomly drawn from a set of 100 passenger pictures) for $4 \mathrm{sec}$. These passengers represented a combination of both genders (male, female) and five racial groups (White, Black, Asian, Middle Eastern, Hispanic). The passenger images were scaled via a pre-test to be comparable in facial expression and perceived attractiveness. After scanning each luggage image, the participant decided whether to stop the bag (if a target was detected) or pass the bag (if a target was not detected). At the end of each trial, participants received feedback in the form of a text message on the screen indicating whether they had made a correct decision or not. The probability of target presence was $50 \%$ for statistical purposes, which was unknown to participants. The primary dependent variables were hit rate (or, true positive rate: The probability of correctly stopping a bag with a target) and false alarm rate (or, false positive rate: The probability of incorrectly stopping a bag without a target).

\section{RESULTS}

Results revealed no statistically significant differences in hit rate as a function of gender and race of passenger. However, passenger gender and race had significant effects on the generation of false alarms. An alpha value of 0.05 or lower is considered statistically significant in the tests below.

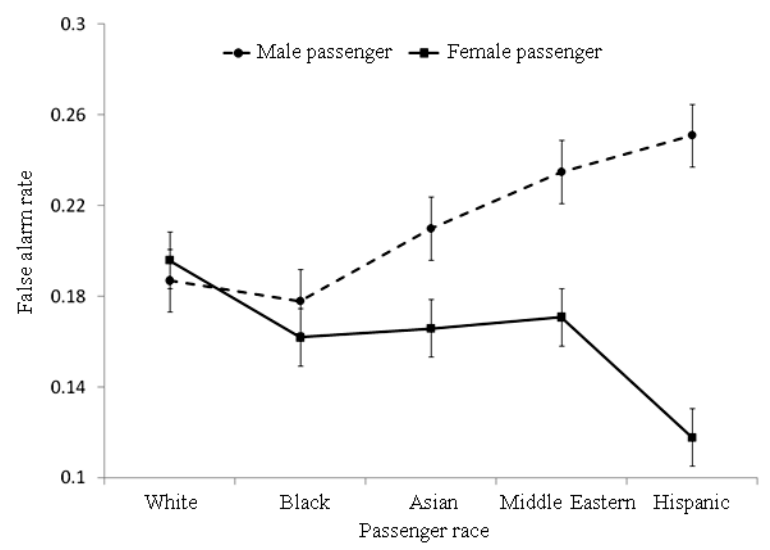

Fig. 1: False alarm rates as a function of gender and race of passengers. Error bars indicate standard errors
For false alarm rate, a 2 (passenger gender: male vs. female) $\times 5$ (passenger race: White, Black, Asian, Middle Eastern, Hispanic) within-subjects ANOVA revealed a significant main effect for passenger gender $\left(\mathrm{F}(1,35)=9.63, \mathrm{p}=0.004, \eta^{2}=0.216\right)$, but not for race $(\mathrm{F}(4,140)=0.386, \mathrm{p}=0.819)$. The interaction between gender and race was significant $(F(4,140)=2.468$, $\mathrm{p}=0.048, \eta^{2}=0.066$ ).

As indicated by the main effect for gender, participants generated significantly more false alarms when the luggage image was preceded by a male passenger $(\mathrm{M}=0.211, \mathrm{SD}=0.031)$ than a female passenger $(\mathrm{M}=0.13, \mathrm{SD}=0.01)$ (Fig. 1). As hypothesized, participants were inherently more suspicious of men than women suggesting the presence of a strong gender bias. The significant interaction between gender and race (Fig. 1) indicates that the probability of incorrectly stopping a 'clear' bag increased significantly when the passenger was male for two races alone-Middle Easterners (male passengers: $\mathrm{M}=0.235, \mathrm{SD}=0.207$; female passengers: $\mathrm{M}=0.171, \quad \mathrm{SD}=0.147 ; \mathrm{t}(35)=1.775$, $\mathrm{p}=0.045$ ) and Hispanics (male passengers: $\mathrm{M}=0.252$, $\mathrm{SD}=0.246$; female passengers: $\mathrm{M}=0.117, \mathrm{SD}=0.242$; $\mathrm{t}(35)=2.473, \mathrm{p}=0.018)$.

\section{DISCUSSION}

On a positive note, the results of this study indicated that gender and racial biases were not manifested in hit rates. This suggests that correct detections of threat objects were based on a largely unbiased decision process. In other words, the correct detection of weapons appears to be based more on an objective evaluation of the contents of a piece of luggage and less on extraneous biases in the screening process. This, of course, is conjecture and the data itself does not provide reasons for why hit rates were impacted less by social-cognitive biases than false alarms.

Contrary to the findings for hit rates, strong biases were observed in the generation of false alarms. In this study, the tendency to perceive men as more suspicious than women was clearly manifested only for two races that are considered "minorities" in the United StatesHispanics and Middle Easterners. The participants in this study were all either White or Black; therefore, passengers of Middle Eastern and Hispanic race were possibly perceived as "outgroups" and therefore threatening. This resulted in significantly higher false alarms for luggage that purportedly belonged to passengers of these two minority races. 
Interestingly, passengers of Asian race were not subjected to the above bias, despite also being a minority race in the United States. Therefore, the results of this study cannot be explained by simple "ingroupoutgroup" differences in people perception discussed in social psychological research (Lee and Ottati, 2002; Anastasi and Rhodes, 2006). The alarming incidence of false positives for passengers of Middle Eastern and Hispanic origin alone cannot simply be due to the fact that they were considered the "outgroup", since this bias was not observed for passengers of Asian origin. Instead, this trend points to the existence of deep rooted biases against members of a specific demographic group influenced by recent world events, that is ultimately manifested in civilian behavior.

Evidently, participants used their personal biases as 'anchors' to help in the decision making process particularly when they had little time to pay close attention to the luggage itself. Research has revealed that people of minority races have been associated with negative behavioral connotations. Studies examining racial biases among police decisions to shoot (Plant and Peruche, 2005; Correll et al., 2007) have shown that both police and civilians are more likely to shoot a minority suspect versus a White suspect, even when the former did not have a gun and the latter did; persons of minority races are perceived as dangerous even when not in possession of a weapon (Correll et al., 2007). The results of our study provide strong support for this bias in airline carry-on luggage screening. The probability of unnecessarily and incorrectly stopping non-threat luggage was significantly higher for male passengers of minority races alone and particularly those races that have been associated with negative connotations in the United States in the past decade.

\section{CONCLUSION}

The results of this study are not entirely surprising in that they support popularly held notions of racial and gender bias in the luggage screening process. However, it is both remarkable and alarming that such biases can be readily elicited among a group of relatively "naïve" civilian college students with no vested interests or experience in the luggage screening task. Such racial and gender biases, if allowed to propagate on a larger scale, could potentially be used by perpetrators of crimes to manipulate a dangerous object past security. Incidents of elderly adults and children being unwitting 'carriers' of weapons are classic examples of perpetrators using such socialcognitive biases to their advantage. If unmitigated, these biases can portend tragic consequences for national security and can weaken the moral fabric of a security conscious nation.

\section{REFERENCES}

Anastasi, J.S. and M.G. Rhodes, 2006. Evidence for own-age bias in face recognition. North Am. J. Psychol., 2: 237-252.

Baker, K., A. Craddock and A. Orwig, 2002. An educator's guide to access issues. University of Illinois Urbana. http://www.ed.uiuc.edu/wp/access/index.html

Boldry, J.G. and D.A. Kashy, 1999. Intergroup perception in naturally occurring groups of differential status: A social relations perspective. J. Person. Soc. Psych., 77: 1200-1212.

Bonanno, G.A., D. Keltner, J.G. Noll, F.W. Putnam and P.K. Trickett et al., 2002. When the face reveals what words do not: Facial expressions of emotion, smiling and the willingness to disclose childhood sexual abuse. J. Person. Soc. Psych., 83: 94-110. DOI: 10.1037//0022-3514.83.1.94

Correll, J., B. Park, C.M. Judd, B. Wittenbrink and M.S. Sadler et al., 2007. Across the thin blue line: Police officers and racial bias in the decision to shoot. J. Person. Soc. Psych., 92: 1006-1023. DOI: 10.1037/0022-3514.92.6.1006

Lee, Y.T. and V. Ottati, 2002. Attitudes toward US immigration policy: The roles of in-group-outgroup bias, economic concern and obedience to law. J. Soc. Psych., 142: 617-634. DOI: 10.1137/0022-3214.11.10.1006

McCarley, J.S., A.F. Kramer, C.D. Wickens, E.C. Vidoni and W.R. Boot, 2004. Visual skills in airportsecurity screening. Psychol. Sci., 15: 302-306. DOI: 10.1111/j.0956-7976.2004.00673.x

McKay, S. and U. Tate, 2001. Student attitudes regarding gender bias in performance evaluations of salespeople. J. Bus. Psychol., 16: 249-258.

Plant, E.A. and B.M. Peruche, 2005. The consequences of race for police officers' responses to criminal suspects. Psychol. Sci., 16: 180-183. DOI: 10.1111/j.0956-7976.2005.00800.x 